\title{
Efficacy of neem chippings for mosquito larval control under field conditions
}

\author{
Susan S Imbahale ${ }^{1,2^{*}}$ and Wolfgang R Mukabana ${ }^{1,3}$
}

\begin{abstract}
Background: An in depth understanding of mosquito breeding biology and factors regulating population sizes is fundamental for vector population control. This paper presents results from a survey of mosquito breeding habitats and the efficacy of neem chippings as a potential larvicide that can be integrated in mosquito control on Nyabondo Plateau in western Kenya.

Results: Six main mosquito habitat types namely artificial ponds, abandoned fish ponds, active fish ponds, open drains, temporary pools and swamps were found in Nyabondo. Early anopheline instars were mainly recovered from temporary pools, artificial ponds and abandoned fish ponds. The mosquitoes collected were Anopheles gambiae sensu lato (35\%), An. coustani (46\%) and Culex spp (19\%). Both early and late instar larvae of anopheline and culicine mosquitoes were more abundant in the controls than in the Bti and neem treated habitats. Within treated habitats, early instar anopheline mosquitoes were recovered more from habitats provided with neem and fish compared to Bti treated habitats. All treated habitats recorded higher numbers of early instar larvae than late instars or pupae, indicating that gravid female mosquitoes still oviposited within treated habitats.
\end{abstract}

Conclusions: Neem chippings are a good tool for mosquito larval source management under field conditions. However, more research needs to be done to quantify the contribution of this tool to the overall mosquito borne disease transmission.

Keywords: Neem chippings, Azadirachta indica, Bacillus thuringiensis israelensis, Bti, Anopheline, Nyabondo, Botanicals, Culicine, Mosquitoes

\section{Background}

Mosquitoes are among the most devastating disease vectors in sub-Saharan Africa [1]. Their proliferation is mainly facilitated by climatic and ecological changes associated with developmental activities such us construction, farming, brick making etc. [2-8]. Mosquito vector control programmes have relied heavily on the use of insecticides through indoor residual spraying (IRS) and insecticide treated bed nets (ITNs) [1,9]. Both strategies focus on indoor adult mosquito vector populations because shortening the life of this developmental stage can have a major impact on vectorial capacity [10]. Furthermore, adult female mosquitoes

\footnotetext{
* Correspondence: sueimbahale@yahoo.com

${ }^{1}$ International Centre of Insect Physiology and Ecology, P.O. Box 30772 GPO,

Nairobi, Kenya

${ }^{2}$ Department of Applied and Technical Biology, Technical University of Kenya, P.O Box 52428City Square, Nairobi, Kenya

Full list of author information is available at the end of the article
}

make themselves vulnerable to control interventions when they seek for blood meals from human hosts [11]. Despite the successes reported in using insecticides for mosquito control, this is threatened by the rise of insecticide resistance in mosquito vectors [12], which necessitates the development and trialing of complementary and/or supplementary strategies. Although unlikely to replace insecticide-based adult mosquito control, larval control methods offer sustainable supplements to existing mosquito vector control efforts [13-16]. One advantage of targeting larvae is that they cannot escape from their breeding sites as an avoidance mechanism against control measures [14].

Mosquito larval control commonly referred to as larval source management (LSM) is particularly valuable in regions where the primary mosquito vectors are exophilic and/or bite before people are in bed, so rendering IRS and ITNs less effective [17-20]. Larval source management is the management of aquatic habitats that are 
potential larval habitats for mosquitoes, in order to prevent the completion of development of the immature stages [21]. Some LSM strategies that are widely used include (a) application of the spore-forming bacteria Bacillus thuringiensis var. israelensis (Bti) and B. sphaericus $(B s)$ that are very selective agents against mosquito and midge larvae [14,16,22-24], (b) environmental management [25] and (c) use of botanicals [26]. Although insecticides of plant origin have existed for many years, they have not been fully utilized against vectors of public health importance [27]. One of the most studied botanical sources is the neem tree Azadiracta indica whose extracts have shown considerable lethal activity against insect pests of agricultural and public health importance [28-31]. The LSM strategies available for the control of mosquito larvae can only be effective when tailored appropriately to local ecology and infrastructure [32]. This study was carried out on Nyabondo Plateau, a rural setting in western Kenya, to (a) characterize mosquito breeding habitats and (b) assess the efficacy of neem chippings as a mosquito larval source management strategy.

\section{Methods}

\section{Study area}

This study was carried out on Nyabondo Plateau. Nyabondo plateau is located in Upper Nyakach Division, Nyando sub county, western Kenya. The plateau lies at an altitude of $1,658 \mathrm{~m}$ above sea level and at $0^{\circ} 23^{\prime} 0 \mathrm{~S}$ and $34^{\circ} 58^{\prime} 60 \mathrm{E}$. Upper Nyakach Division has a population density of 368 persons per square $\mathrm{km}$ and an estimated population size of 332,313 persons [33]. The population is dominated by the local Dholuo speaking people. The local inhabitants depend on brick making and selling as the main economic activity. Small scale crop and animal husbandry are also practiced. Crop agriculture is dominated by maize, bananas, cassava, sorghum and sweet potatoes. Domesticated animals mainly include cattle, sheep, goats and donkeys. Previous entomological surveys in Nyabondo found that larval Anopheles mosquitoes bred in both temporary and permanent habitats. Adult An. gambiae complex mosquitoes collected during the surveys found An. arabiensis (99.3\%) to be the main malaria vector species, followed by An. gambiae (0.7\%) [34].

\section{Mosquito larval sampling}

The primary entomological outcome of this study was the presence of immature mosquitoes which served to evaluate the effectiveness of various larval control treatments. Larval sampling was done once weekly using a sweep net [6]. Up to a maximum of five sweeps were taken along the edges of each habitat depending on its surface area and size. Sweeps were taken until no more organisms, visible to the naked eye, were being observed. Sweep net contents were emptied into a white tray to enhance visibility, identification and counting of sampled organisms. About 10 minutes was allowed for the water to settle down before the next sweep was made. Collected specimens were sorted into mosquito larvae and other aquatic organisms. Mosquito larvae were sorted into anopheline and culicine subtypes, counted and recorded as early instars (L1 and L2), late instars (L3 and L4) or pupae. Pupae were not separated into the anopheline and culicine subtypes. Other organisms were returned back into the water after recording their identity and numbers. Collected pupae were transported to the field laboratory of the International Centre of Insect Physiology and Ecology (icipe's) located at the Nyabondo Mission Hospital where they were allowed to emerge into adults before being identified taxonomically [35].

\section{Mosquito larval habitat characterization}

The aim of these investigations was to assess the diversity of mosquito larval breeding habitats on Nyabondo plateau so as to inform any current and future larval source management endeavors. All potential breeding habitats were identified and checked for the presence or absence of mosquito larvae. In addition habitat type, size and origin (i.e. if man made or natural) plus water movements and presence or absence of aquatic vegetation within the habitats was determined and recorded.

\section{Efficacy of neem chippings as a mosquito larval control agent}

The main aim of these investigations was to assess the efficacy of neem chippings as a mosquito larval control agent under field conditions. The work was carried out on Nyabondo plateau in western Kenya. Four treatments were used in these evaluations. The treatments included neem chippings, mosquito predatory fish (Oreochromis niloticus), the bio-larvicide Bacillus thuringiensis israelensis (Bti), and untreated (negative) controls. The negative controls included an assortment of mosquito larval habitats none of which was treated with neem chippings, mosquito predatory fish or Bti. Habitat types in the negative control category included abandoned fish ponds, artificial ponds, open drains, swamps and temporary pools such as brick pits.

The test treatment i.e. neem chippings were prepared from the stem of the neem tree Azadirachta indica [36], which belongs to the Family Meliaceae. The crude neem chippings were packed in $30 \times 50 \mathrm{~cm}$ nylon bags each weighing about $1.5 \mathrm{~kg}$. Only one such bag was placed in each artificial pond habitat. A total of 10 artificial ponds were treated with neem bags. The pesticidal activity of neem is attributed to Azadirachtin, which is the active eco-friendly ingredient [37-39]. Most efficacy studies have concentrated on using neem seed and leaf extracts in which Azadirachtin is most concentrated [28]. One school of thought considers the crude neem plant as being less expensive and effective than the purified compounds or 
extracts for controlling insects of medical and veterinary importance [40]. Oreochromis niloticus (Perciformes: Cichlidae), an edible fish species commonly known as Tilapia and which is farmed and eaten in the Nyabondo area, was used as a biological control agent. This acted as a pseudo positive control because the ten fish ponds that were selected and stocked with fingerlings of Tilapia $\left(4 \mathrm{fish} / \mathrm{m}^{2}\right.$ ) were not regularly cleared off of emergent vegetation as would be desired when using fish as a mosquito larval control agent [3]. Water-dispersible and granulated formulations of the commercial larvicide VectoBac ${ }^{\circ}$ containing Bacillus thuringiensis var. israelensis (Bti; Valent Biosciences Corporation, Libertyville, IL, USA), i.e. the true positive control, was applied to all other temporary habitats and selected permanent habitats that contained mosquito larvae on Nyabondo plateau. The Bti was broadcasted on the larval habitats at weekly intervals at an optimum dosage and concentration of $200 \mathrm{~g} / \mathrm{ha}$ as done elsewhere [37].

All experimental mosquito habitats were inspected once weekly for presence or absence of mosquito larvae.

\section{Ethical considerations}

Ethical approval for this study was given by the Kenya National Ethical Review Committee located at the Kenya Medical Research Institute (SSC Protocol number 2675). A private land tenure system where individual families have exclusive rights to residential and agricultural parcels is observed in Nyabondo. Thus, verbal consent to carry out the research outlined in this article was sought from families.

\section{Data analysis}

All raw data were entered in Microsoft Excel spreadsheets from where they were exported into the Statistical Package for Social Scientists (SPSS version 16.0) for analysis. The mosquito larval habitat characteristics recorded included presence or absence of mosquito larvae, the mosquito larval species type, presence or absence of water movements, presence or absence of aquatic vegetation, habitat type and origin. These data were explored using descriptive statistics functions in the SPSS. Chi-square analysis was used to determine the impact of variables collected on the presence or absence of immature mosquitoes within the different habitats. Binary regression was used to quantify the impact of significant variables on the presence of immature stages of mosquitoes. The numbers of mosquito larvae collected in the test treatment and the positive controls were statistically compared to those collected from the negative control treatments using posthoc Bonferroni tests.

\section{Results}

The study was done from January to December 2012. Nyabondo plateau was searched and all stagnant waters checked for the presence or absence of mosquito larvae in January 2012. Experiments testing the efficacy of neem chippings as a mosquito larval control agent under field conditions were carried out from February to December 2012.

\section{Mosquito larval habitat characterization}

A total of $339(\mathrm{~N})$ potential habitats were identified among which $57 \%$ had mosquito larvae. The rest $(43 \%)$ had no larvae. A total of six mosquito larval habitat types were identified (Figure 1). These included artificial ponds, open drains, swamps, active fish ponds, abandoned fish ponds and temporary pools (Table 1). Temporary pools were composed of foot/hoof prints, tire tracks, brick pits and ground pools. Temporary pools held water for approximately two weeks after rains and dried out when rains ceased. Permanent habitats held water for approximately 2-3 months after the rains. Majority of the habitats sampled were permanent $(62 \%)$ in nature, with sizes ranging from 10 - $100 \mathrm{~m}$ in surface perimeter (72\%) and occurring as a result of human activities (96\%). Exploratory statistical analyses found the presence or absence of mosquito larvae inside habitats to be affected by habitat type $\left(x^{2}=\right.$ 21.974; $\mathrm{df}=5 ; \mathrm{P}=0.001)$, habitat stability i.e. whether the habitats were temporary or permanent $\left(X^{2}=22.317\right.$; $\mathrm{df}=1 ; \mathrm{P}=0.001)$, source of water $\quad\left(\mathrm{X}^{2}=5.254 ; \mathrm{df}=1\right.$; $\mathrm{P}=0.022)$, habitat size $\left(\mathrm{X}^{2}=9.822 ; \mathrm{df}=2 ; \mathrm{P}=0.007\right)$ and vegetation $\left(X^{2}=12.547 ; \mathrm{df}=1 ; \mathrm{P}=0.001\right)$ (Table 2). Habitat origin i.e. whether natural or manmade $(P=0.350)$ and water movement within habitats $(P=0.381)$ had no effect on presence or absence of mosquito larvae (Table 2). Further analysis using binary logistic regression found habitat stability (temporary or permanent) to be the only significant determinant of the presence or absence of mosquito larvae in habitats (OR 0.353; C.I. 0.203 - 0.614; $\mathrm{P}=0.001$ ). Permanent habitats had a $65 \%$ higher chance of containing mosquito larvae than temporary habitats.

\section{Efficacy of neem chippings as a mosquito larval control agent in the field}

A total of 7,782 (93\% early and 7\% late instar) anopheline and 11,590 (71\% early and $29 \%$ late instar) culicine mosquito larvae were sampled during the study. The presence or absence of larvae varied significantly among habitats assigned different treatments $(\mathrm{P}=0.001)$. Early instar anopheline mosquitoes had 54.8\%, 5.6\% and 34\% higher probabilities of being present in the negative controls compared to Bti (OR 0.452; C.I. $0.401-0.509 ; \mathrm{P}=0.001$ ), fish (OR 0.944; CI $0.652-1.366 ; \mathrm{P}=0.759)$ and neem $(\mathrm{OR}$ 0.659; C.I. $0.531-0.820 ; \mathrm{P}=0.001)$ treated habitats, respectively (Figure 2 ). There were significantly higher numbers of early anopheline instars in habitats treated with neem (mean difference $=0.31 \pm 0.061 ; \mathrm{P}=0.001$ ) and fish (mean difference $=0.57 \pm 0.096 ; \mathrm{P}=0.001$ ) than 

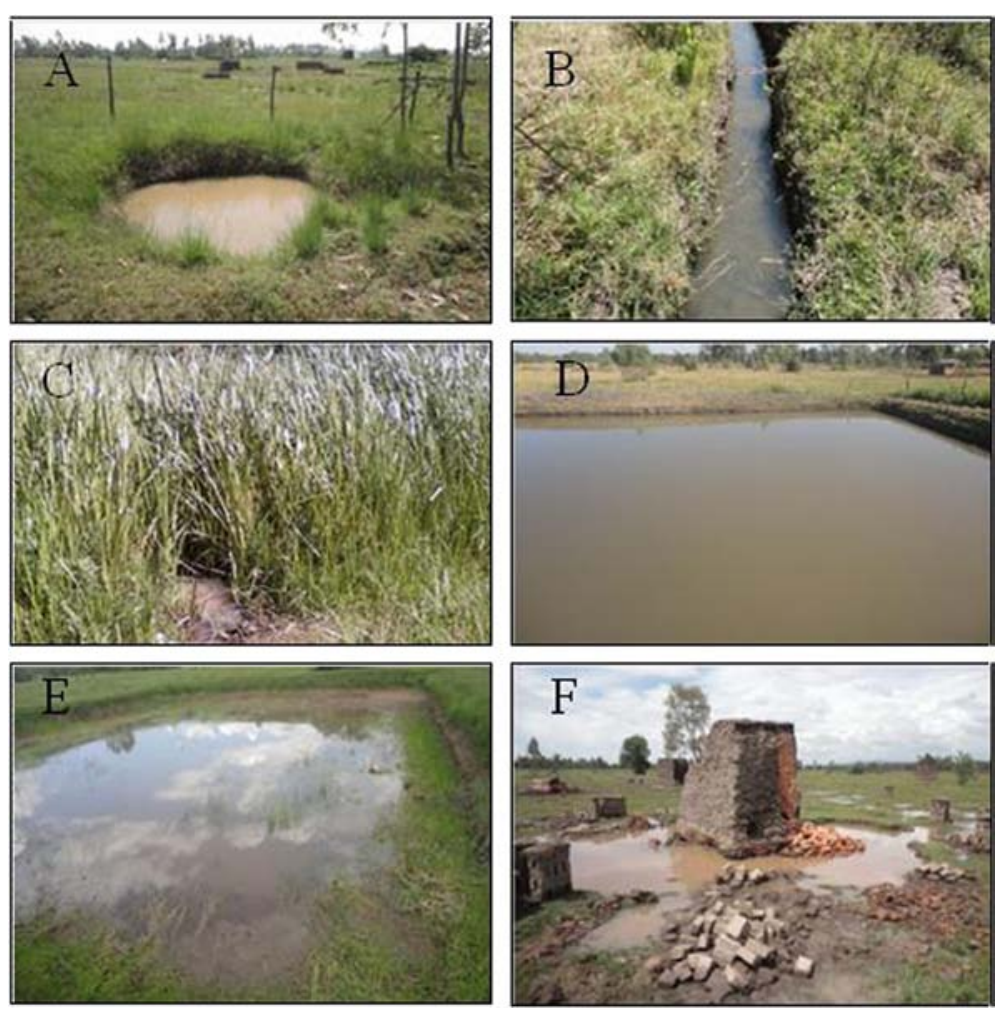

Figure 1 Physical appearance of mosquito larval habitat types identified on Nyabondo plateau in western Kenya. The habitats included artificial ponds (A), open drains (B), swamps (C), active fish ponds (D), abandoned fish ponds (E) and temporal pools (F).

Table 1 Mosquito larval habitat types found on Nyabondo plateau in western Kenya

\begin{tabular}{|c|c|c|}
\hline Habitat Type & $\mathrm{N}$ (percent) & Description \\
\hline Artificial pond: & $88(70.5 \%)$ & $\begin{array}{l}\text { A small manmade depression containing } \\
\text { still water stored for local purposes e.g. } \\
\text { brick making, watering cattle, domestic } \\
\text { use etc. }\end{array}$ \\
\hline Open drain: & $50(42.0 \%)$ & A channel dug to draw off water. \\
\hline Swamp: & $15(66.6 \%)$ & $\begin{array}{l}\text { A low-lying wet land with tall reeds and } \\
\text { grassy vegetation }\end{array}$ \\
\hline $\begin{array}{l}\text { Active fish } \\
\text { pond: }\end{array}$ & $6(0.0 \%)$ & $\begin{array}{l}\text { A controlled inland body of standing } \\
\text { freshwater stocked with fish }\end{array}$ \\
\hline $\begin{array}{l}\text { Abandoned } \\
\text { fish pond: }\end{array}$ & $68(63.2 \%)$ & $\begin{array}{l}\text { An unmaintained and/or uncontrolled } \\
\text { inland body of standing freshwater with } \\
\text { or without fish }\end{array}$ \\
\hline \multirow[t]{5}{*}{$\begin{array}{l}\text { Temporary } \\
\text { pools: }\end{array}$} & $112(47.3 \%)$ & $\begin{array}{l}\text { Shallow depressions holding water only } \\
\text { during rains e.g. }\end{array}$ \\
\hline & & $\begin{array}{l}\text { (a) foot prints: grooves made on the } \\
\text { ground by man and/or cattle }\end{array}$ \\
\hline & & $\begin{array}{l}\text { (b) tire tracks: grooves made on the } \\
\text { ground by vehicles }\end{array}$ \\
\hline & & $\begin{array}{l}\text { (c) brick pits: depressions made by digging } \\
\text { out topsoil to make bricks }\end{array}$ \\
\hline & & $\begin{array}{l}\text { (d) ground pools: naturally formed small } \\
\text { area with still water }\end{array}$ \\
\hline
\end{tabular}

those treated with Bti. On the other hand the control had $77.4 \%, 59.8 \%$ and $84.5 \%$ higher chance of containing late anopheline larvae compared to Bti (OR 0.226 C.I. $0.169-0.302 \mathrm{P}<0.05)$, fish (OR 0.402 C.I. $0.188-$ $0.860 \mathrm{P}<0.05)$ and neem (OR 0.155 C.I. $0.066-0.362$ $\mathrm{P}<0.05)$ treated habitats, respectively (Figure 2 ). There were no significant differences in late anopheline instars within habitats treated with neem, Bti and fish $(\mathrm{P}>0.05)$.

Early culicine larvae were likely to be present in control rather than Bti (OR 0.466; C.I. $0.419-0.518 ; \mathrm{P}=0.001$ ) and neem (OR 0.422; C.I. $0.342-0.521 ; \mathrm{P}=0.001)$ treated habitats (Figure 3). There were significantly higher numbers of early culicine instars in habitats treated with fish than those treated with Bti (mean difference $=0.96 \pm$ $0.085 ; \mathrm{P}=0.001$ ) and neem (mean difference $=1.06 \pm 0.099$; $\mathrm{P}=0.001)$. No significant differences in numbers of early culicine instars were observed in habitats treated with neem and Bti $(\mathrm{P}>0.874)$. Late culicine larvae were likely to be present in control rather than $B t i$ (OR 0.305; C.I. $0.268-$ 0.348; $\mathrm{P}=0.001$ ) and neem (OR 0.279; C.I. $0.210-0.370$; $\mathrm{P}=0.001$ ) treated habitats (Figure 3 ). Similar to early instars, significantly higher numbers of late culicine instars were in habitats treated with fish than those treated with Bti (mean difference $=0.53 \pm 0.053 ; \mathrm{P}=0.001$ ) and neem (mean difference $=0.55 \pm 0.062 ; \mathrm{P}=0.001$ ). No significant 
Table 2 Factors affecting presence of mosquito larvae in breeding habitats on Nyabondo plateau, western Kenya

\begin{tabular}{|c|c|c|c|c|c|c|}
\hline Factor & Factor level & Frequency (n) & Percentage & Chi-square & df & Significance \\
\hline \multirow[t]{2}{*}{ Habitat stability } & Permanent & 214 & 63.13 & & & \\
\hline & Temporary & 125 & 36.87 & 22.317 & 1 & 0.000 \\
\hline \multirow[t]{2}{*}{ Habitat origin } & Man-made & 326 & 96.17 & & & \\
\hline & Natural & 13 & 3.83 & 0.873 & 1 & 0.350 \\
\hline \multirow[t]{2}{*}{ Water origin } & Surface run-off & 279 & 82.30 & & & \\
\hline & Underground & 60 & 17.70 & 5.254 & 1 & 0.022 \\
\hline \multirow[t]{3}{*}{ Habitat size } & $<10$ & 45 & 13.27 & & & \\
\hline & $>100$ & 50 & 14.75 & & & \\
\hline & $10-100$ & 244 & 71.98 & 9.822 & 2 & 0.007 \\
\hline \multirow[t]{2}{*}{ Water movement } & No & 301 & 88.79 & & & \\
\hline & Yes & 38 & 11.21 & 0.768 & 1 & 0.381 \\
\hline \multirow[t]{2}{*}{ Vegetation } & Absent & 149 & 43.95 & & & \\
\hline & Present & 190 & 56.05 & 11.547 & 1 & 0.001 \\
\hline
\end{tabular}

differences in numbers of late culicine instars were observed between habitats treated with neem and Bti (P > 1.0).

A total of 145 pupae were collected with $70 \%$ success in adult emergence. Pupae were more likely to be present in control habitats than habitats exposed to treatments (Figure 4). Among the mosquitoes that emerged successfully were $A n$. gambiae sensu lato (35\%), An. coustani $(46 \%)$ and culicine (19\%) mosquito species. The presence of pupae was not different among the habitats except for Bti-treated habitats (OR 0.393; C.I. 0.229 - 0.674; $\mathrm{P}=0.001$ ), which had a $60.7 \%$ reduced chance of having pupae compared with the controls.

The other aquatic organisms that were encountered during field sampling included hemiptera, coleoptera and ephemeroptera among others.

\section{Discussion}

Mosquito breeding habitats in Nyabondo varied from temporary pools, artificial ponds, open drains, swamps, abandoned and active fish ponds. The presence or absence of immature mosquitoes within the different habitat types varied depending on habitat stability i.e. whether permanent or temporary, source of water, habitat size and vegetation cover. More anopheline larvae were encountered in artificial ponds, temporary pools and abandoned fish ponds, whereas culicine larvae were likely to be present in artificial ponds, abandoned fish ponds and swamps. Among the mosquito species recorded in the area were $A n$. gambiae sensu lato, An. coustani and Culex species. This is the first time An. coustani is being reported in Nyabondo. All treated and untreated habitats contained early instar larvae. However, habitats provided with treatments had reduced

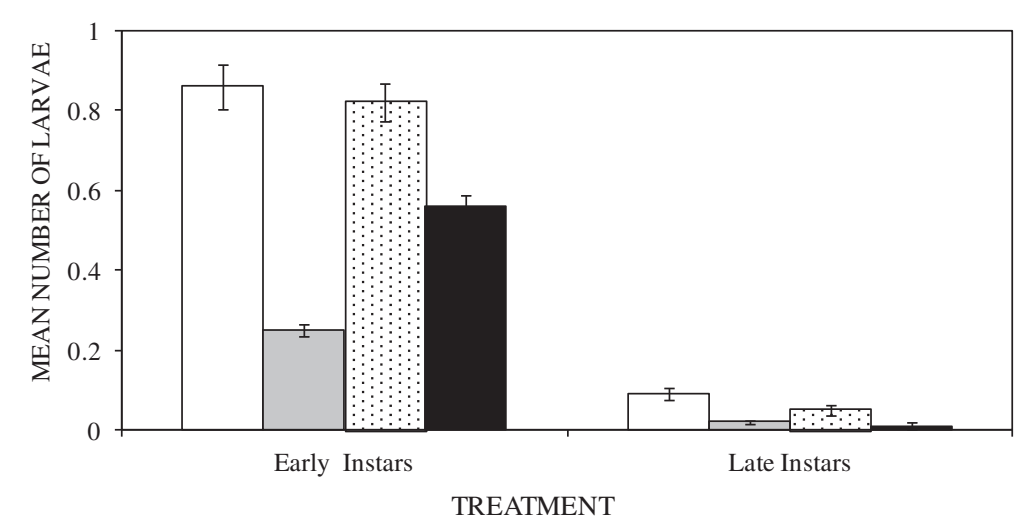

Figure 2 Mean numbers of early and late anopheline larvae in untreated habitats (empty bar) or in habitats treated with the commercial biolarvicide Bacillus thuringiensis israeliensis (gray bar), the edible fish Oreochromis niloticus (hatched bar) and chippings of the neem tree Azadiracta indica (black bar). 


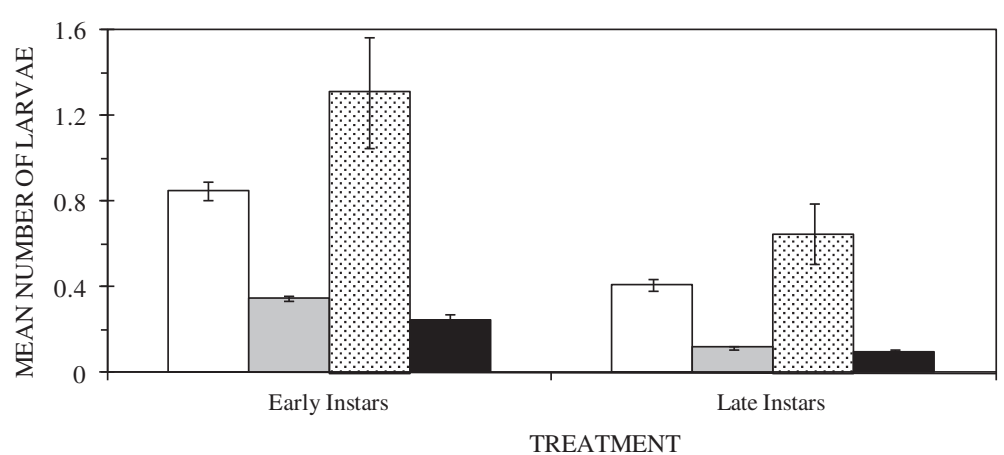

Figure 3 Mean numbers of early and late culicine mosquito larvae in untreated habitats (empty bar) or in habitats treated with the commercial biolarvicide Bacillus thuringiensis israeliensis (gray bar), the edible fish Oreochromis niloticus (hatched bar) and chippings of the neem tree Azadiracta indica (black bar).

numbers of late instars of both anopheline and culicine mosquitoes. In general habitats treated with neem or Bti compared well showing no differences among all the stages and species.

Mosquito breeding habitats have been documented in many parts of Western Kenya [4-7,41]. Existing literature shows that breeding habitats are heterogeneous and that they vary from one location to another even in the same region. On Nyabondo Plateau the major breeding habitats were artificial ponds followed by temporary pools and abandoned fish ponds, all resulting from human activity. Artificial ponds were more abundant on the plateau as they are mostly used by brick makers for water preservation but unfortunately they provide the most preferred breeding habitats for mosquitoes. Apart from artificial ponds, early anopheline larvae were more often sampled from abandoned ponds, temporary pools and open drains. Culicine larvae outnumbered anophelines where they occurred in the same habitats except in the open drains. Habitats such as abandoned fish ponds and artificial ponds held water for long periods of time, which might have allowed for the establishment of a predator population that fed on the mosquito larvae before they developed into pupae. Field observations during sampling found such habitats to contain tadpoles, Hemiptera, Coleoptera and Ephemeroptera among the known mosquito predators and/or competitors. Secondly, the larvae were in most occasions more than the pupae, suggesting there may have been attrition resulting from natural competition for available resources. In this study it was assumed that the productive habitats, which contained more immature mosquitoes, produced more adult mosquitoes. Therefore, more larvae meant more biting population of mosquitoes and consequently an increased risk of mosquito borne disease. The assumption is supported by the findings by Ndenga and colleagues [6], who found the most productive habitats for adult mosquitoes to be those that recorded higher numbers of larvae.

All treated habitats recorded higher numbers of early instar larvae than late instars or pupae, indicating that gravid female mosquitoes still oviposited within treated habitats, exposing their progeny to lethal effects of treatments. Compared to the control, larvae from neem treated habitats had a much lower probability of growing

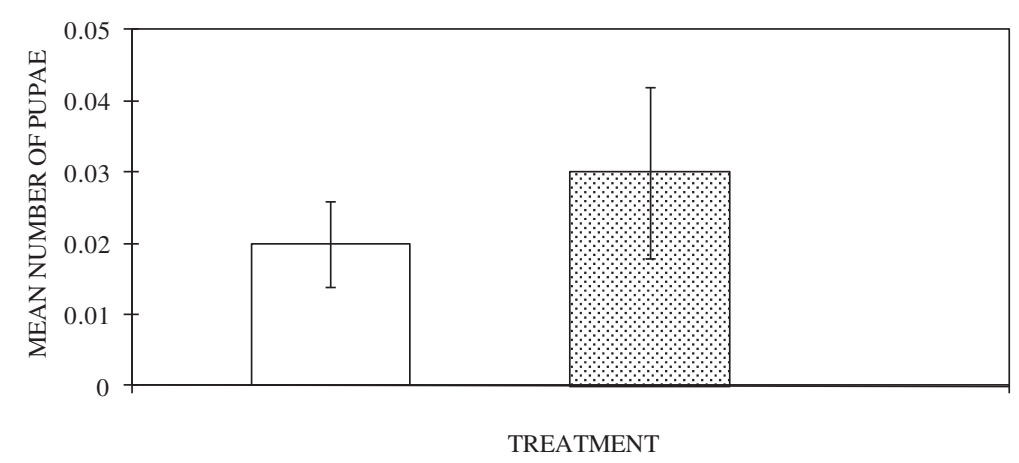

Figure 4 Mean numbers of mosquito pupae in untreated habitats (empty bar) and in habitats treated with the edible fish Oreochromis niloticus (hatched bar). No pupae were found in habitats treated with the commercial biolarvicide Bacillus thuringiensis israeliensis or with chippings of the neem tree Azadiracta indica. 
to maturity because extremely few late instars and pupae of both species groups were present in these habitats. These findings support those of Howard and others [40], who reported that neem did not deter ovipositing females in a laboratory trial. Crude neem or partially-purified plant extracts which are less expensive, have been found to be highly effective for the control of mosquitoes rather than the purified compounds or pure extracts of the plant [40]. Crude extracts also discourage the development of resistance in the vectors [28]. The stem was not the only important part but the order of larvicidal potency among other parts of the plant was found to increase from the leaf to root to seed to bark [42]. This study is among the few that have reported field application of crude neem extracts. The application of neem chippings for the control of mosquitoes is encouraged because it minimizes the accumulation of harmful residues in the environment.

The bio-larvicide $(B t i)$ was applied to all temporary habitats and a selected number of permanent habitats making up $71 \%$ of the proportion of habitats under this intervention. This was purposely done as Bti being the true positive control, has already been shown to work effectively. Consistent with existing literature on Bti [14-16,24,43], the immature anopheline and culicine mosquito populations were significantly reduced within the respective habitats. Habitats treated with Oreochromis niloticus had both early and late instars of anopheline and culicine mosquitoes throughout the sampling period. However, culicine larvae were more abundant in the presence of fish than in the control habitats suggesting that these could have been a less preferred mosquito species group compared to the anophelines. Predatory fish though suitable for use in artificial pond habitats was not as effective as the neem chippings and Bti. This may be because the active fish ponds used in this study were not regularly maintained to remove any emergent vegetation where larvae would hide. Although the field trials carried out demonstrate that neem chippings can contribute to a reduction in mosquito abundance, its impact on disease transmission remains a gap. Nevertheless, this study has clearly described mosquito breeding habitats and the efficacy of neem chippings as a mosquito larval control agent under field conditions.

\section{Conclusion}

Neem chippings can be used as a locally available alternative that compliments well proven mosquito larval control agents namely the commercial bio-larvicide Bacillus thuringiensis israelensis (Bti). However, more research needs to be done to quantify the contribution of neem chippings to the overall mosquito borne disease transmission under field conditions.

\section{Competing interests}

The authors declare no conflict of interest. The funding organization did not have any role in the collection of data, its analysis and interpretation of the results.

\section{Authors' contributions}

This study was designed by SSI and WRM. SSI analyzed the data. SSI and WRM drafted the manuscript. Both authors have read and approved the final version of the manuscript.

\section{Acknowledgements}

We would like to thank the field assistants who worked for icipe's Nyabondo mosquito larval control program for collection of field data. We extend our appreciation to Mr. Mike Omondi for supervising field data collection. The community in Upper Nyakach is appreciated for their cooperation during the study period. We thank the Biovision Foundation, Switzerland for their longstanding financial support.

\section{Author details}

${ }^{1}$ International Centre of Insect Physiology and Ecology, P.O. Box 30772 GPO, Nairobi, Kenya. ${ }^{2}$ Department of Applied and Technical Biology, Technical University of Kenya, P.O Box 52428City Square, Nairobi, Kenya. ${ }^{3}$ School of Biological Sciences, University of Nairobi, P.O. Box 30197 GPO, Nairobi, Kenya.

Received: 17 September 2014 Accepted: 20 February 2015 H.t?

\section{References}

1. WHO. World Health Organization Global Malaria Programme. Geneva, Switzerland: World Malaria Report; 2012.

2. Carlson JC, Byrd BD, Omlin FX. Field assessments in western Kenya link malaria vectors to environmentally disturbed habitats during the dry season. BMC Public Health. 2004;4:33.

3. Howard AF, Zhou G, Omlin FX. Malaria mosquito control using edible fish in western Kenya: preliminary findings of a controlled study. BMC Public Health. 2007;7:199.

4. Munga S, Minakawa N, Zhou G, Mushinzimana E, Barrack OO, Githeko AK, et al. Association between land cover and habitat productivity of malaria vectors in western Kenyan highlands. Am J Trop Med Hyg. 2006;74:69-75.

5. Mutuku FM, Bayoh MN, Gimnig JE, Vulule JM, Kamau L, Walker ED, et al. Pupal habitat productivity of Anopheles gambiae complex mosquitoes in a rural village in western Kenya. Am J Trop Med Hyg. 2006;74:54-61.

6. Ndenga BA, Simbauni JA, Mbugi JP, Githeko AK, Fillinger U. Productivity of Malaria Vectors from Different Habitat Types in the Western Kenya Highlands. PLoS One. 2011;6(4):e19473.

7. Imbahale SS, Paaijmans KP, Mukabana WR, Lammeren R, Githeko AK, Takken W. A longitudinal study on Anopheles mosquito larval abundance in distinct geographical and environmental settings in western Kenya. Malar J. 2011;10:81.

8. Castro MC, Kanamori S, Kannady K, Mkude S, Killeen GF, Fillinger U. The importance of drains for the larval development of lymphatic filariasis and malaria vectors in Dar es Salaam, United Republic of Tanzania. PLoS Negl Trop Dis. 2010;4(5):e693.

9. WHO. World Health Organization Global Malaria Programme. Geneva, Switzerland: World Malaria Report; 2013a.

10. Macdonald G. Epidemiological basis of malaria control. Bull World Health Org. 1956:15:613-26.

11. Kelly DW. Why are some people bitten more than others? Trends Parasitol. 2001;17:578-81.

12. Ranson H, N'guessan R, Lines J, Moiroux N, Nkuni Z, Corbel V. Pyrethroid resistance in African anopheline mosquitoes: what are the implications for malaria control? Trends Parasitol. 2011;27(2):91-8.

13. Lengeler C, Sharp B. Indoor residual spraying and insecticide-treated nets: reducing Malaria's burden. Washington, DC: Evidence of effectiveness for Decision makers. Global Health Council; 2003. p. 17-24.

14. Fillinger U, Ndenga B, Githeko A, Lindsay SW. Integrated malaria vector control with microbial larvicides and insecticide treated nets in the western Kenyan highlands: a controlled trial. Bull World Health Organ. 2009;87:655-65.

15. Killeen GF, Fillinger U, Knols BG. Advantages of larval control for African malaria vectors: low mobility and behavioural responsiveness of immature mosquito stages allow high effective coverage. Malar J. 2002;1:8. 
16. Geissbuhler Y, Kannady K, Chaki PP, Emidi B, Govella NJ, Mayagaya V, et al. Microbial Larvicide Application by a Large-Scale, Community-Based Program Reduces Malaria Infection Prevalence in Urban Dar Es Salaam. Tanzania PLoS ONE. 2009;4(3):e5107.

17. WHO 2013b Larval Source Management Operational Manual. A supplementary measure for malaria vector control (www.who.int). Vector Control Unit Global Malaria Programme Geneva.

18. Shililu Jl, Mbogo MC, Mutero CM, Gunter JT, Swalm C, Regens JL, et al. Spatial distribution of Anopheles gambiae and Anopheles funestus and malaria transmission in Suba district western Kenya. Insect Sci Appl. 2003;23:187-96.

19. Walker K, Lynch M. Contributions of Anopheles larval control to malaria suppression in tropical Africa: review of achievements and potential. Med Vet Entomol. 2007;21:2-21.

20. Russell TL, Govella NJ, Azizi S, Drakeley CJ, Kachur SP, Killeen GF. Increased proportions of outdoor feeding among residual malaria vector populations following increased use of ITNs in rural Tanzania. Malar J. 2011;10:80.

21. Reddy MR, Overgaard HJ, Abaga S, Reddy VP, Caccone A, Kiszewski A, et al. Outdoor host seeking behavious of Anopheles gambiae mosquitoes following initiation of malaria vector control on Bioko Island. Equatorial Guinea Malar J. 2011;10:184.

22. Floore TG. Mosquito larval control practices: past and present. J Am Mosq Control Assoc. 2006;22:527-33.

23. Takken W, Knols BG. Malaria vector control: current and future strategies. Trends Parasitol. 2009;25:101-4.

24. Majambere S, Lindsay SW, Green C, Kandeh B, Fillinger U. Microbial larvicides for malaria control in The Gambia. Malar J. 2007;6:76.

25. Keiser J, Singer BH, Utzinger J. Reducing the burden of malaria in different eco-epidemiological settings with environmental management: a systematic review. Lancet Infect Dis. 2005;5:695-708.

26. Indian Council of Medical Research Bulletin. Prospects of using herbal products in the control of mosquito vectors. 2003;3:1-10

27. Das NG, Goswami D, Younes MW, Abdel-Wahab H, Mansour AH. Preliminary evaluation of mosquito larvicidal efficacy of plant extracts. J Vector Borne Dis. 2007:44:145-8

28. Mulla MS, Su T. Activity and biological effects of neem products against arthropods of medical and veterinary importance. J Am Mosq Control Assoc. 1999;15:133-52.

29. Bekele D, Petros B, Tekie H, Asfaw Z. Larvicidal and Adulticidal effects of extracts from some indegenour plants against malaria vector Anopheles arabiensis in Ethiopia. J Biofertl Biopestici. 2014;5:2.

30. Ghosh A, Chowdhury N, Chandra G. Plant extracts as potential mosquito larvicides. Indian J Med Research. 2012;135:581-98.

31. Innocent E, Hassanali A, Kisinza WNW, Mutalemwa PPP, Magesa S, Kayombo E. Anti-mosquito plants as an alternative or incremental method for malaria vector control among rural communities of Bagamoyo District. Tanzania J Ethnobiology Ethnomedicine. 2014;10:56.

32. Thwing J, Fillinger U, Gimnig J, Newman R, Lindsay S. Mosquito larval source management for controlling malaria. Cochrane Database of Systematic Reviews. 2011; Issue 1. [doi:10.1002/14651858.CD008923].

33. Imbahale SS, Abonyo OK, Aduogo OP, Githure JI, Mukabana WR. Conflict between the need for income and the necessity of controlling endemic malaria. J Ecosystem Ecography. 2013;3:129.

34. Mutero C, Mbogo C, Mwangangi J, Imbahale S, Kibe L, Orindi B, et al. An Assessment of Participatory Integrated Vector Management for Malaria Control in Kenya. Environmental Health Perspectives. (Accepted).

35. Gillies MT, Coetzee M. A supplement to the Anophelinae of Africa South of the Sahara. Johannesburg: The South African Institute for Medical Research; 1987.

36. Howard AFV, Adongo EA, Hassanali A, Omlin FX, Wanjoya A, Zhou G, et al. Laboratory evaluation of the aqueous extract of Azadirachta indica (neem) wood chippings on Anopheles gambiae s.s. (Diptera: Culicidae) mosquitoes. J Med Entomol. 2009;46:107-14.

37. Fillinger U, Knols BG, Becker N. Efficacy and efficiency of new Bacillus thuringiensis var israelensis and Bacillus sphaericus formulations against Afrotropical anophelines in Western Kenya. Trop Med Int Health. 2003;8:37-47.

38. Dua VK, Pandey AC, Raghavendra K, Gupta A, Sharma T, Dash AP. Larvicida activity of neem oil (Azadirachta indica) formulation against mosquitoes. Malaria J. 2009;8(1):124

39. Mondali NK, Mojumdar A, Chatterje SK, Banerjee A, Datta JK, Gupta S. Antifungal activities and chemical characterization of Neem leaf extracts on the growth of some selected fungal species in vitro culture medium. J Appl Sci Environ Manag. 2009;13(1):49-53.

40. Howard AFV, Adongo EA, Vulule J, Githure J. Effects of a botanical larvicide derived from Azadirachta indica (the neem tree) on oviposition behaviour in Anopheles gambiae s.s. mosquitoes. J Med Plant Res. 2011;5(10):1948-54. 18 May, 2011.

41. Minakawa N, Mutero CM, Githure JI, Beier JC, Yan G. Spatial distribution and habitat characterization of anopheline mosquito larvae in Western Kenya. Am J Trop Med Hyg. 1999;61:1010-6.

42. Alouani A, Rehimi N, Soltani N. Larvicidal activity of a neem tree extract (azadirachtin) against mosquito larvae in the republic of Algeria. Jord J Biol Sci. 2009;2(1):15-22.

43. Tusting LS, Thwing J, Sinclair D, Fillinger U, Gimnig J, Bonner KE, et al. Mosquito larval source management for controlling malaria. Cochrane Database of Systematic Reviews. 2013; Issue 8. [doi:1002/14651858. CD008923.pub2].

\section{Submit your next manuscript to BioMed Central and take full advantage of:}

- Convenient online submission

- Thorough peer review

- No space constraints or color figure charges

- Immediate publication on acceptance

- Inclusion in PubMed, CAS, Scopus and Google Scholar

- Research which is freely available for redistribution 